\title{
Research and Implement of Berthing System of Large Vessels
}

\author{
Guojun Peng ${ }^{1,2}$, Zhixiu $\mathrm{Du}^{1,2^{*}}$ and Xinghua Wang ${ }^{1,2}$ \\ ${ }^{1}$ Research Center of Ship Navigation Service, Fujian 361021, P.R. China \\ ${ }^{2}$ Jimei University, Xiamen, Fujian 361021, P.R. China
}

\begin{abstract}
Over the years, along with the progress and development of science and technology, the number and size of large vessels are enlarging continuously, which brings a lot of pressure to the pilots. To lighten the heavy burden of the pilots and decrease the possibility of the accident during the pilotage, the berthing system of large vessels is researched and implement. The system is an electronic communication equipment based on the technology of AIS, DGPS, WIFI and so on. Since that, the precision of the system is high and performance is well. The implement of the berthing system gives an auxiliary to pilots to control the progress of pilotage and then improve the efficiency and safety.
\end{abstract}

Keywords: AIS technology, berthing device, GPS technology, large vessel.

\section{INTRODUCTION}

The rapid development of the world shipping economy provides the unprecedented opportunity for the domestic ports. The direct result of the development of the port is increasing the density and the work-load of the port. Ship is an important element in the daily port operation. At present, the ship is heading for quickness and large scale. With the reasons of large volume and large tonnage, the traditional method of the pilot has been unable to meet the current safety need of large ship which makes it more difficult to manipulate the ship. In order to further enhance and improve the operation efficiency of the port and guarantee the ship berthing operation safer and more effective, the crew not only need to continuously improve the control technology of large ships, but also must be equipped with the appropriate tools to assist pilotage operation.

According to the statistical data from Chinese Pilotage Association, there are more than 40 national pilot mechanisms in our country. The number of domestic and foreign vessels which were piloted is 366000 only in 2009 . The development of large ships, especially DWT VLCC, bulk carriers and large container ship with five, six hundred thousand turning up, increases the berthing operation complexity. Due to ship's dynamic data time delay or error in ship handling and so on, many dangerous cases are caused in the ship berthing process. A ship collided Shanghai power plant terminal in 2010 November. In 2011 December in Dafeng harbor, a ship ran into another one during the process of its berthing. These accidents brought great loss to the country and the safety of people's life and property. Therefore, it is very important to design berthing auxiliary equipment for the safety of berthing.

\section{THE PROCESS OF LARGE SHIPS BERTHING}

\subsection{The Characteristics of Large Ships}

Because of large ships weight and large loading capacity, the square coefficient is big, and the operation inertia is also great. So the large vessels have the characteristics of slow steering response, poor ability of keeping course, large parking stroke, small cyclotron diameter, quick decrease of speed in the process of operating rudder and so on. Square coefficient of large ship is about 0.8 . Course stability coefficient $T$ is always large which causes poor course stability and steering quality. Cycle shape coefficient $\mathrm{K}$ is always large which means cyclicity is good. Vertical and horizontal margins are between 0.5 and $0.7 \mathrm{~nm}$. It should take the influence of flow into full consideration. It is easy to control ships when faces flow. After operating the rudder the speed of the ships decreases quickly. In full load condition it has large drainage volume, the inertia and stroke are large, handling is always dully, and it is not easy to increase or decrease the speed. The operator has the strong power of observation, accurate judgment and the environmental conditions at the time of the good ability of comprehensive analysis, to take timely and accurate operation methods and preventive measures to deal with the ship which may be abnormal and dangerous at any time.

\subsection{The Requirements of Operating Large Ships for Pi- lots}

Due to the above characteristics of large ships, berthing process for them needs to meet a high standard.

First of all, in order to schedule large ship pilotage pilots must fully understand the above characteristics to respond abnormal conditions timely, promptly eliminate hidden dangers to avoid the occurrence of safety accidents, to eliminate the adverse impact on the ship and to ensure the safety of ship berthing. 
Secondly, the pilots must fully understand the various parameters of ships, including the static parameters (captain, breadth, truck, truck type, draft etc) and dynamic parameters (speed over the ground, course, the distance from the distance to the bank), to take corresponding measures to ensure the safety of berthing.

Once again, the pilots should advance understanding of navigational chart, harbor chart, guide to port, route guide, tide tables, signal books, lighthouse table and all kinds of books, fully study the influence of tidal, flow and wind to ships into the navigable waters. If it is need, timely correction of airflow pressure should be taken to make the position on the line.

\section{DEVELOPMENT OF BERTHING SYSTEM}

Since the implementation of E-NAVIGATION, every country fall over each other to join the research and development of ship navigation products. Research of berthing systems is also put on the agenda at this time by national shipping industry researchers. Development started in each country is different, and technical level is also not the same. So far the research's degree in each country is not identical.

In foreign countries, especially the coastal countries in Europe, research of berthing instrument started earlier than other countries, it seems more mature. For example, AD NAVIGATION in Norway, launched its ADX XR. In the exhibition of 2012 May IHMA (International Harbor Masters Association), the product won the praise from domestic and foreign top experts. MARIMATECH E-Sea Fix PILOT company in Denmark developed the continuous development and improvement, has launched three generation products, such improvement makes the product more light weight, the positioning accuracy higher and the performance better. Because of its advantages of light weight, high precision and easy to use, berthing auxiliary equipment Harbour Pilot Lightweight developed by Navicom Dynamics Company in New Zealand, not only is widely used in domestic, but also is exported to foreign countries, and is praised by the pilot of New Zealand and other countries.

From 1970 s to 1990 s, ports in domestic are generally equipped with shore-based auxiliary facilities such as sonar, radar or air acoustic berthing system, In 1970s sonar docking system was developed in China. However, due to the transducer beam angle restriction, in the range of 200 meters, the signal is susceptible to water surface wave and bottom wave reflection effects, measurement precision and dynamic response speed of the system are affected. Its accuracy and effective distance are restricted. Only the distance is short, its accuracy can be better than sonar systems, but still can not get the desired effect application. Later, air acoustic berthing system and laser berthing system came out. Even under ideal conditions the effective distance of air acoustic berthing system is only 100 meters. If it winds, the effective distance, stability and accuracy are decreased. In addition, its dynamic response speed is decreased. Therefore, this system has not been widely used. Because of its superior performance and high reliability, the laser berthing system had been widely recognized, but later its shortcomings were also found. Divergence of the light, coupled with absorption of the air to the light and scattering which may cause the reflected light of a distant target is weak. Interference caused by spurious signal will result the measurement can't be carried out. The mounting position of the probe, the height of the tide and distance to berthing line also have a great impact on the accuracy. In addition, the received data should be transmitted by special optical which will spend a lot of manpower and material resources.

Later ship-based berthing system came out. Although ship-based berthing system early can provide forward and backward, and the longitudinal velocity of ship and can also provide the moving speed and direction of bow and stern when ship berths. Relative to shore-based berthing system, it greatly improves the safety of ship berthing time, but the precision is relatively low. Compared to foreign berthing system which uses DGPS positioning to acquire positioning information, uses real-time kinematic (RTK) to calculate position, steering angle, speed and other parameters of the ship, domestic berthing system is still at the primary stage.

In order to follow the trend of the times, to speed up the development of ports in China, improve the operation efficiency of the port, control pilot process better and improve the security of pilot, a lot of research units began to study berthing system of large ships. Berthing system presented in this paper is designed based on AIS, DGPS, wireless data transmission technology, WIFI and other advanced technologies. And ultimately it can be operational, can display, and can be carried.

\section{STRUCTURE AND COMPOSITION OF THE SYS- TEM}

\subsection{Hardware}

The hardware part is composed of three parts which are a machine, B machine and displaying terminal.

A machine has a central processing unit, an AIS receiving module, wireless transmission module, DGPS module and WIFI module. Accordingly, B machine only has a central processing unit, DGPS module and the wireless data transmission module.

After the DGPS positioning unit of module B machine receives positioning information, the information is sent to a machine by using wireless data transmission technology. The DGPS positioning unit of the A machine receives positioning information. AIS acquire information of the ship and other ships and the gyroscope collects the information. All the information is sent to displaying terminal. Displaying terminal can be IPAD, iPhone etc. After the data processing module integrates the collected data, the software calculates the pilot data, graphic information berthing operations required for reference use software system, such as the ship's static data, fore and aft relative terminal distance and speed, heading, turning rate, course to the ground and speed over the ground, and then displays them at the interface of ECDIS.

Hardware diagram of berthing system of large vessels is shown in Fig. (1).

\subsubsection{Specification of A Machine}

Cold start time: $<60$ seconds, 


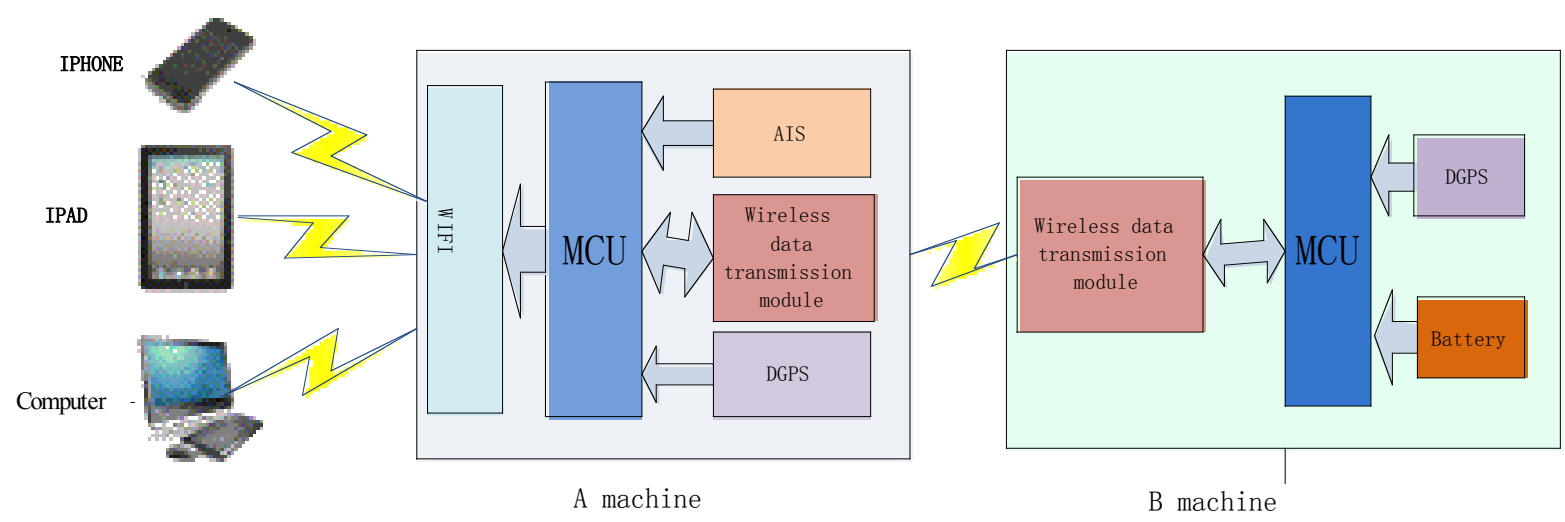

Fig. (1). Hardware diagram of berthing system of large vessels.

Warm start time: $<35$ seconds,

Hot start time: $<20$ seconds,

Reacquisition Time: $<1$ second,

Receive NMEA-0183 GPS data,

GPS positioning accuracy $0.6 \mathrm{~m}$ (2DRMS),

WLAN: Wi-Fi 802.11a/b/g/n,

WIFI Working distance: Not less than $80 \mathrm{~m}$,

WIFI output information: Standard GPS statement standard AIS statement [8],

WIFI input message: Standard AIS statement,

Battery: Built-in lithium battery, 4000mAh, can work continuously for not less than six hours,

Working environment:

Temperature: $-25 \sim+55^{\circ} \mathrm{C}$, Humidity: $4 \sim 95 \%$, Waterproof: IP4, subject to any direction without harmful effects of water splashing, Weight: $1.5 \mathrm{KG}$.

\subsubsection{Specifications of B Machine}

Cold start time: $<60$ seconds,

Warm start time: $<35$ seconds,

Hot start time: $<20$ seconds,
Reacquisition Time: $<1$ second, Receive NMEA-0183 GPS data, GPS positioning accuracy: 0.6 meters (2DRMS), Baud Rate: 9600 bps,

Output information: Standard GPS statement,

Frequency: $5 \mathrm{~Hz}$,

Effective communication distance with A machine: Not less than $500 \mathrm{~m}$, Power: $<2 \mathrm{~W}$,

Battery: Lithium battery, can work for not less than six hours,

Working environment:

Temperature: $-25 \sim+55{ }^{\circ} \mathrm{C}$, Humidity: $4 \sim 95 \%$,Weight: $500 \mathrm{~g}$.

\subsection{Software}

According to the principle of modular design, the software part of the auxiliary berthing instrument of large ship is designed in blocks. The structure of software system is shown in Fig. (2).

As shown in Fig. (2), the software design uses a hierarchical structure, this structure is independent of hardware which means the design is not dependent on specific hardware.

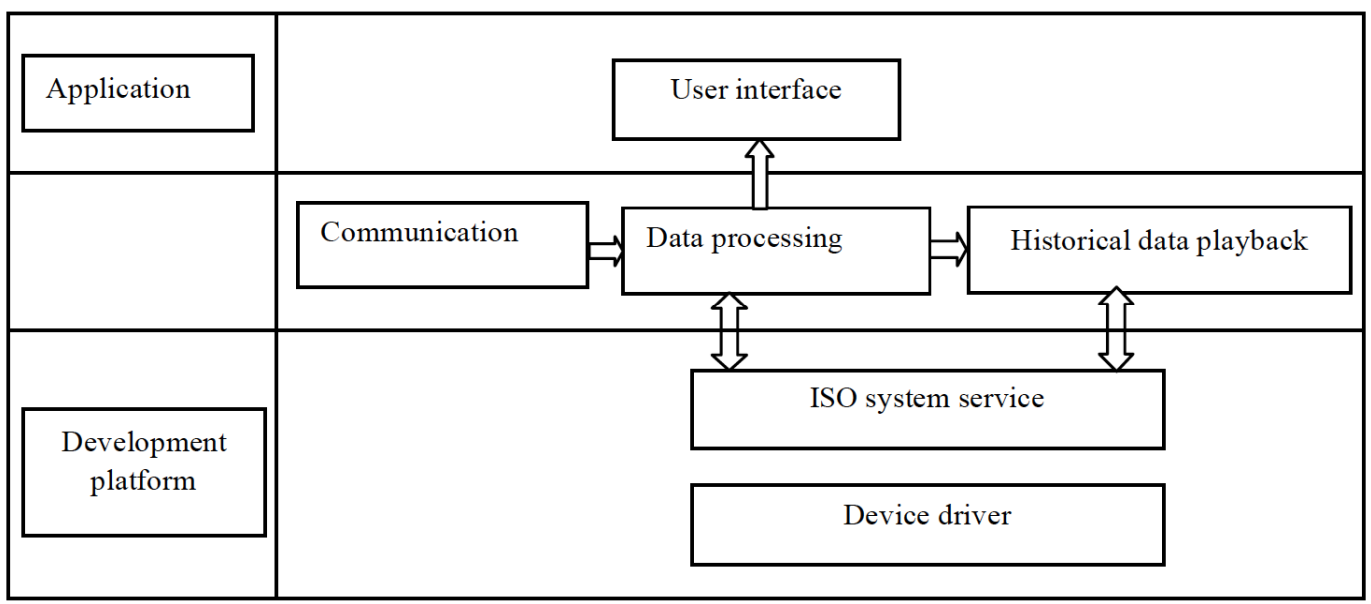

Fig. (2). The structure of software system. 


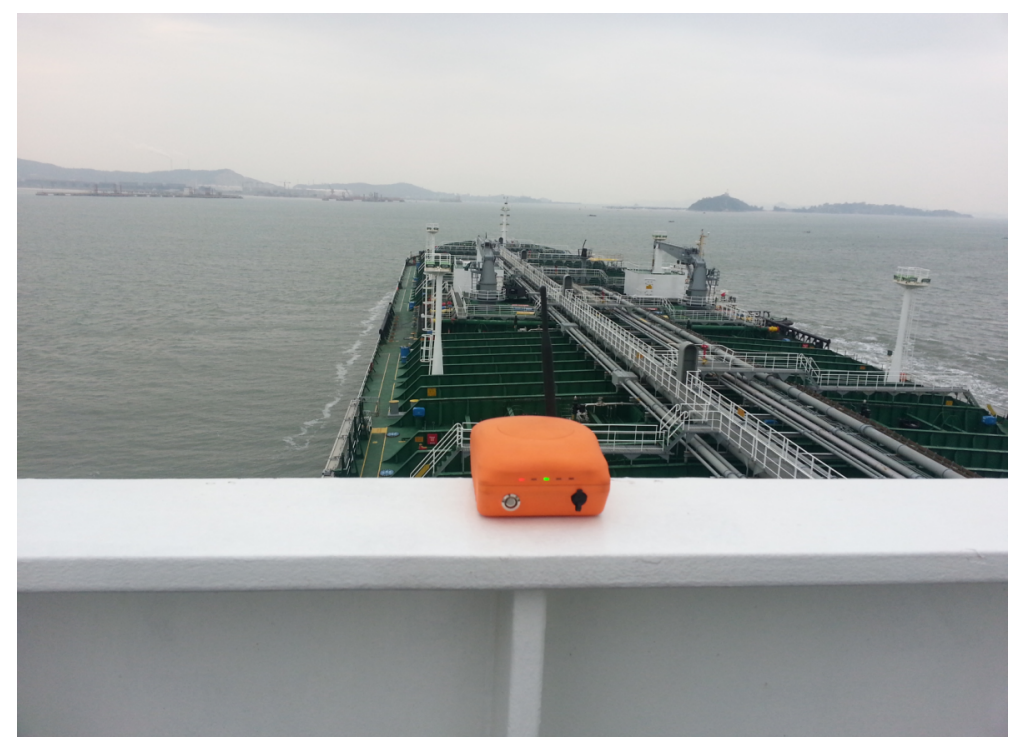

Fig. (3). Pilot process.

Fig. (4). Displaying interface.

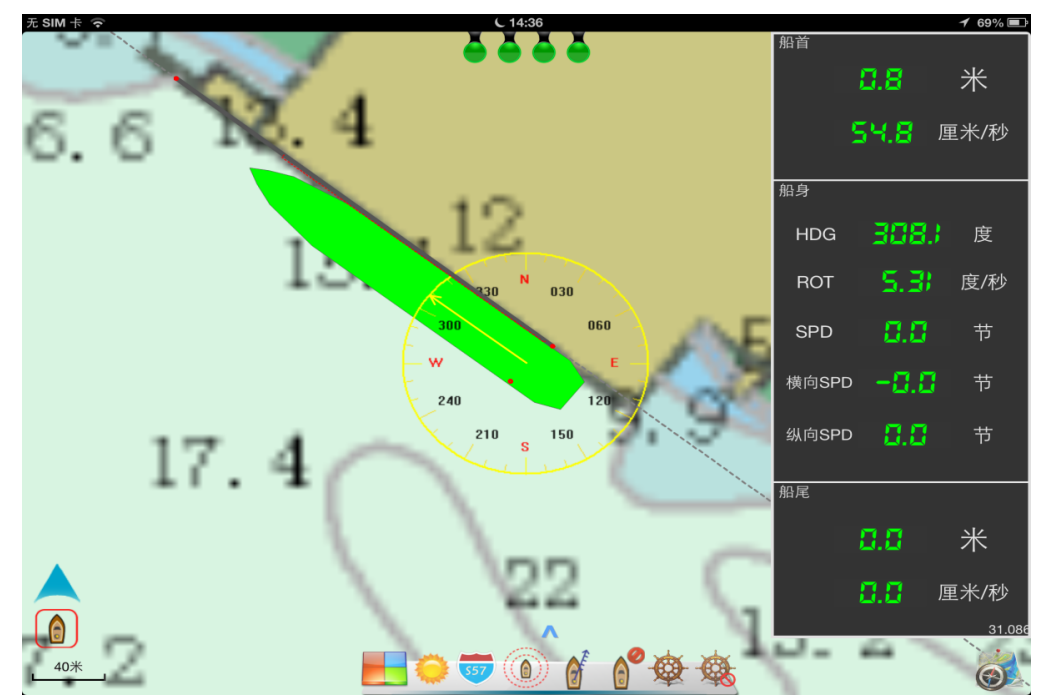

The design of the software system has the following functions:

\section{1). Map operation}

The system provides map enlargement, shrink, translation, reduction and other basic operation, and also provides the positioning function such as center displaying and scope center.

\section{2). Image display}

The system can take the image as the background. If the remote sensing image is taken as background, channel, aids to navigation, berth, anchorage, water depth points and other navigation elements can be added, which forms a set of virtual, more intuitive "electronic chart", so as to provide assistant support for pilot scheduling and management.

\section{3). Operation mode switching}

System supports switching freely among three operating modes which are the real-time monitoring, real-time piloting navigation and history navigation. If there is no specific statement, it is in the mode of real-time monitoring.

In the mode of real-time monitoring operation, by connecting the center data service system, the system can timely access to marine dynamic data, and according to different data of each ship, it can show different color, shape, size, vector line, track lines, so as to realize the monitoring of the waters close to all ships, and operate freely.

In the mode of the real-time pilotage operation, on the one hand, system can obtain the ship dynamic data through the data center service system. On the other hand, it can also obtain dynamic data of ships through Bluetooth by connecting external DGPS device or shipborne AIS Pilot-Plug equipment and select the ship which needs pilotage as the ship. The system will reflect the ship's position, speed, heading and other information. In the real-time piloting condition, the ship will overlay display compass circle. At the same time, the system will calculate the distance between the mouse position and the ship's position. The pilot can operate the navigation command conveniently. In addition, in order 
to adapt to the pilot operation habit, the system also provides free display, center display, eccentric display three display modes to control the displaying position in the window, so the pilot can observe and refer to it conveniently.

In the mode of history navigation, the system can select a pilot history recorded data file for playback, simulation, pausing, continuing and switching simulation rate. By which, the pilot and management personnel can view, learn and analyze after that.

\section{4). Ship display}

The system can display the shape of the ship at different scales according to the length and width of the ship. In a small scale, triangle stands for the ship. The triangle center of gravity position is as the position of ship's GPS antenna. In a large scale, enneagon is used as ship model.

The system also supports vector lines, track, name, call sign, MMSI number and other annotations and provide control of display and hidden.

According to the types of ship, the system draws different types of ships by different colors, allowing users to visually observe the distribution of all types of vessels and navigation dynamics. Type of ship is divided into the lead boats, tugs, ferries, pilot boats and so on.

\section{5). Ship Information Query}

By left-clicking the mouse in the window a specific ship is selected and displays important information about the ship selected. The information mainly includes MMSI, name, length, width, longitude, latitude, speed and course.

\section{6). Ships query positioning}

System supports MMSI, name, call sign field for fuzzy query, the records meet the conditions listed, and can be centrally located on the specified record.

\section{7). Scheduling queries}

System downloads the update pilotage plan for managers, dispatchers inquiries, by the central data service system, to provide assistance for the pilotage scheduling support.

\section{8). Berth inquiry}

The system supports berth query shows: When the mouse moves to a berth on the map area, the system will automatically add the appropriate length of the berths, former draft, rear draft and other information to pilots for berthing operations.

\section{9). Tidal information inquiry}

In the tidal information display panel, tide information can be queried in the specified month 24 hours a day each hour. You can check climax every day in given month, the lowest point of time and tide. You can also specify the tidal change process in some day in the form of curves for reference to managing and scheduling pilotage of large ships.

\section{0). Berthing settings}

For large ship berthing, it can parameter settings, such as length, breadth, location of berthing equipment, and enter information such as the conditions for berthing mode.

\section{1). Berthing mode switching}

According to conditions of berthing mode, system can automatically berth mode and pilot mode switch. For example, when distance between the ship and the pier is set less than 5 breadth, system will become in the mode of berthing automatically when the system special window will accurately display a variety of dynamic data and information on the aquatic environment during the berthing of the ship.

\section{2). Berthing alarm}

System is able to calculate ship dynamic data according to the measured data by detect device. While being able to monitor speed and direction of wind and flow and other environment data, if the surrounding environment is not suitable for berthing harsh, bootable security alerts.

When the ship berthing is too fast or the angle is too large, alarm signals alert personnel in field operations to prevent damage from the pier (ship) facility.

\section{CONCLUSION}

This paper studies the characteristics of large vessels, and establishes an appropriate mathematical model of large vessels berthing system, which will be the realization of a berthing powerful auxiliary tool for large ships. The research process overcame many technical difficulties. In the study of how to achieve the fusion of information output and the electronic chart, it takes great amount of manpower and resources. Although the system has been initially achieved its intended function, there are still some technical problems, such as the accuracy is not high enough, the communication distance is not far enough, waterproof seismic capacity is not good enough and other issues.

As a very important part of the shipping industry, port plays a key role in economic development of a region and a country. With the development of port, in order to further enhance and improve the operational effectiveness and efficiency of domestic port, pilots have to possess a higher level of technology. Application of berthing system will reduce the pilot's work pressure, pilot operating efficiency will be greatly improved and it will be safer. If we can improve the system's shortcomings and put it into application, it is believed that the environment will greatly improve port operation environment.

\section{CONFLICT OF INTEREST}

The author confirms that this article content has no conflict of interest.

\section{ACKNOWLEDGEMENTS}

This paper belongs to the project of the "IndustryAcademy Cooperation Science and Technology Major Projects of University in Fujian Province", No. 2013H61010100.

\section{REFERENCES}

[1] L. B. Zhou, "Maneuvering requirements of very large ships", Chinese Maritime, vol. 5, pp. 44-46, May 2011. 
[2] H. Chen, Research and Implementation of Laser berthing System. Dalian: Dalian University of technology, 2005.

[3] N. Yu, Application of Universal automatic identification system (AIS). Dalian: Dalian Maritime University, 2007.

[4] G. N. Feng and J. L. Yang, Wide area differential GPS system and wide area differential Augmentation System. Beijing: China Academic Journal Electronic Publishing, pp. 516-521, 2009.

[5] H. Zhang, J. Zhang, and C. Liu, "Development status and future trends of Global Positioning System (GPS) technology", Chinese Modern Measuring Instruments and Measurement Techniques, vol. 1, pp. 70-92, January 2011.
[6] Z. L. Liu, "Evaluation on developing level of unban agglomeration derived from resources exploration", Journal of Applied Sciences, vol. 13, no. 21, pp. 4702-4707, 2013.

[7] J. M. Guo, Latest development of GPS and GLONASS, $2002 \mathrm{Xu}$ Jianmin. Status and Development of Satellite Application. Beijing: China Science and Technology Press, 2001.

[8] G. L. Qiu, "Development and application of WIFI technology", Heilongjiang Science and Technology Information, vol. 10, pp. 65, 2009.

[9] L. Ran and L. F. Xu, "Application of Hierarchical modular design in Labor System", in Modern computer, November 2004.

Received: September 16, 2014

Revised: December 23, 2014

Accepted: December 31, 2014

(C) Du et al.; Licensee Bentham Open.

This is an open access article licensed under the terms of the (https://creativecommons.org/licenses/by/4.0/legalcode), which permits unrestricted, non-commercial use, distribution and reproduction in any medium, provided the work is properly cited. 